Sheridan College

SOURCE: Sheridan Institutional Repository

Publications and Scholarship

Faculty of Humanities \& Social Sciences

(FHASS)

$12-6-2011$

\title{
Good Food, Good People: Understanding the Cultural Repertoire of Ethical Eating
}

Josee Johnston

Michelle Szabo

Sheridan College, michelle.szabo@sheridancollege.ca

Alexandra Rodney

Follow this and additional works at: https://source.sheridancollege.ca/fhass_publications

Part of the Civic and Community Engagement Commons, Food Studies Commons, Other Social and Behavioral Sciences Commons, and the Politics and Social Change Commons

\section{SOURCE Citation}

Johnston, J., Szabo, M., \& Rodney, A. (2011) Good food, good people: Understanding the cultural repertoire of ethical eating. Journal of Consumer Culture 11(3), 293-318. doi:10.1177/

1469540511417996

\section{(c) $(1) \Theta \Theta$}

This work is licensed under a Creative Commons Attribution-Noncommercial-No Derivative Works 4.0 License. This Article is brought to you for free and open access by the Faculty of Humanities \& Social Sciences (FHASS) at SOURCE: Sheridan Institutional Repository. It has been accepted for inclusion in Publications and Scholarship by an authorized administrator of SOURCE: Sheridan Institutional Repository. For more information, please contact source@sheridancollege.ca. 


\title{
Good food, good people: Understanding the cultural repertoire of ethical eating
}

(C) The Author(s) 2011 Reprints and permissions: sagepub.co.uk/journalsPermissions.nav DOI: 10.1 I77/|4695405||4|7996 joc.sagepub.com @SAGE

\section{Josee Johnston}

University of Toronto, Canada

\section{Michelle Szabo}

York University, Canada

\author{
Alexandra Rodney \\ University of Toronto, Canada
}

\begin{abstract}
Ethical consumption is understood by scholars as a key way that individuals can address social and ecological problems. While a hopeful trend, it raises the question of whether ethical consumption is primarily an elite social practice, especially since niche markets for ethical food products (for example, organics, fair trade) are thought to attract wealthy, educated consumers. Scholars do not fully understand the extent to which privileged populations think about food ethics in everyday shopping, or how groups with limited resources conceptualize ethical consumption. To address these knowledge gaps, the first goal of this paper is to better understand how consumers from different class backgrounds understand ethical eating and work these ideas into everyday food practices. We draw from 40 in-depth interviews with 20 families in two Toronto neighborhoods. Our second goal is to investigate which participants have privileged access to ethical eating, and which participants appear relatively marginalized. Drawing conceptually from cultural sociology, we explore how ethical eating constitutes a cultural repertoire shaped by factors such as class and ethno-cultural background, and how symbolic boundaries are drawn through eating practices. We find that privilege does appear to facilitate access to dominant ethical eating repertoires, and that environmental considerations figure strongly in these repertoires. While low income and racialized communities draw less on dominant ethical eating repertoires, their eating practices are by no means amoral; we document creative adaptations of dominant ethical eating
\end{abstract}

\section{Corresponding author:}

Josee Johnston, Department of Sociology, University of Toronto, 725 Spandina Ave, Toronto, Canada M5S 2J4 Email: josee.johnston@utoronto.ca 
repertoires to fit low income circumstances, as well as the use of different cultural frameworks to address moral issues around eating.

\section{Keywords}

class, cultural repertoire, ethical consumption, food

Ethical consumption is understood by scholars as a key way in which individuals understand and find solutions to social and ecological problems (Arnould, 2007; Barnett et al., 2005b; Micheletti, 2003). Consumers are encouraged to join social change projects via their consumption habits, such as protecting the environment by eating organic foods or drinking shade-grown coffee. While some people may indeed think of their consumption as a form of citizenship, these practices raise the question of whether ethical consumption is primarily an elite social practice. Put in food-specific terms, is 'eating for change' largely the domain of organic-loving yuppy locavores? This is a more complex question than it might initially appear. On the one hand, we know that many so-called ethical products - organic produce, grass-fed meat, fair trade coffee, free-range eggs - are more expensive than their conventional counterparts. In addition, many of the shopping and eating spaces articulating a discourse of ethical consumption, such as Whole Foods Market, are positioned to serve economic elites (Cole, 2008; Guthman, 2008; Hinrichs, 2000; Johnston, 2008). On the other hand, a simple dichotomy between rich/ethical and poor/unethical is politically and empirically problematic. On political grounds, it is highly suspect to map moral virtues onto economically privileged populations who have greater access to foods deemed 'ethical', a conclusion that continues a dubious tradition of morally castigating marginalized populations (Alatas, 1977; Guthman, 2003; Schwartz, 2000). On empirical grounds, scholars lack data demonstrating that privileged populations necessarily think more deeply about food ethics, even though they have resources to buy more 'ethical' products. In addition, we know relatively little about how less privileged populations think (or don't think) about the discourse of ethical eating, and what practices they engage with on limited incomes. ${ }^{1}$ Academic ideas about 'ethical consumption' are expanding, but are not always grounded in empirical studies of 'ethical consumer practices within the complexity of everyday life', particularly studies of general populations and not just self-defined ethical consumers (Adams and Raisborough, 2010: 257).

To address these knowledge gaps, we set out two primary research goals. First, we seek to better understand how consumers understand ethical eating, and how they work these ideas into their daily eating and shopping practices. To do this, we draw from 40 in-depth interviews conducted with 20 families (parents and teenagers) in two urban Toronto neighborhoods: one predominantly upper-middle class neighborhood, and one gentrifying working class neighborhood. Our second goal is to investigate which participants appear to have privileged access to ethical eating, and which participants appear relatively marginalized. 
A qualitative research project does not generate statistical generalizations, but by generating understanding from a specific empirical context, our data can nonetheless speak to potential barriers to full participation in ethical eating projects. Drawing conceptually from cultural sociology, we think about ethical eating as a multifaceted cultural repertoire rather than a monolithic practice or ideology. We explore how marginalization from an ethical eating repertoire is shaped by class and ethno-cultural background, and how symbolic boundaries are drawn through these eating practices.

The paper is structured as follows. First, we describe what we mean by ethical eating discourse, and speak to existing literature on ethical eating and shopping. We also put forward tools from cultural sociology that can generate a nuanced understanding of how people draw from ethical eating discourse in their daily lives. Second, we describe our interview data, and document how coding and analysis were carried out. Third, we analyze the major themes of ethical eating observed in our interviews, and how they were understood. We discuss which participants had heightened access to a dominant ethical eating discourse, which participants appear relatively marginalized, and how alternative issues related to ethics and eating were apparent within the talk of marginalized groups.

\section{Thinking about and theorizing ethical eating}

What exactly do we mean by 'ethical eating'? Starr (2009) defines ethical consumption broadly as 'people purchasing and using products and resources according not only to the personal pleasures and values they provide but also to ideas of what is right and good, versus wrong and bad, in a moral sense' (p. 916). While this definition provides a useful starting point, contemporary rhetoric around ethical eating is defined not by a universal sense of 'right and good', but by particular issues that have gained public attention - issues like organic certification, local provenance, and the humane treatment of animals in food production. Some issues that might be deemed 'ethical' on philosophical terms do not enjoy a great deal of public attention. In the context of North American food discourse, environmental issues tend to overshadow issues related to hunger, social justice or agricultural labor (Johnston and Baumann, 2010: 139-140).

Our goal here is not to adjudicate which food consumption practices are inherently ethical or unethical, but to study how food practices are shaped by social discourses. Thinking about ethical eating as a discourse helps us appreciate how systems of thought organize our ideas of eating, and shape what food issues appear most pressing in the dominant public sphere (Johnston and Baumann, 2010: 38). Ethical eating is not a simple set of rules for eating, but can be understood as an overarching cultural discourse with numerous instantiations - organic, fair trade, local, cruelty-free and so forth - as well as an organizing logic linking individual commodity consumption with social and environmental transformation. Despite this overarching logic, ethical eating discourse (like all discourse) contains numerous contradictions (Johnston, 2008; Sassatelli, 2006: 224-226). For example, green 
campaigns to 'eat local' frequently operate at cross-purposes with social justice campaigns to support fair trade foods (Morgan, 2010). Not all groups think about these contradictions the same way, (for example, grass-roots activists versus large food corporations), and these different perspectives often clash in the public sphere, thereby shaping dominant perceptions of what constitutes critical consumption (Sassatelli, 2006: 222). While social movement actors have had significant influence in shaping a broader ethical consumption discourse, powerful economic actors are well positioned to dominate public discourse on ethical consumption, and position their perspectives as universal standards that all citizens should live up to. In food discourse, privileged perspectives tend to be normalized and presented as 'classless' - despite the structural inequalities making it difficult for marginalized groups to eat with maximum efficiency, healthfulness, deliciousness and distinction (DeVault, 1991: 200, 226; Johnston and Baumann, 2010: 189-193). Our objective in this paper is to speak to how ethical food discourse is experienced and enacted by consumers with varying degrees of privilege.

For obvious reasons, marketers and businesses have been keenly interested in better understanding what motivates ethical eating, especially given the expansion of ethical markets in recent years (Starr, 2009: 918). From a market perspective, ethical food discourse has centered on niche products such as organic produce, 'cruelty-free' meats and fair trade coffee (Cole, 2008; Hinrichs, 2000; Roberts, 1996). The motivations underlying ethical consumption have proven surprisingly complex, and Starr reports that 'there is a large but inconclusive literature on determinants of ethical consumption, where it has proven difficult to find systematic effects of socio-demographic characteristics, knowledge of the issues, or concern about them' (2009: 917). Despite these ambiguities, market research generally suggest that cost is a major barrier to participation in ethical consumption markets; consumers who are willing to pay more for ethical products are often well educated and affluent (Aldanondo-Oachoa and Almansa-Saez, 2009; De Pelsmacker et al., 2005; Diamantopoulos et al., 2003; Fotopoulos and Krystallis, 2002; Govindasamy et al., 1998; Gracia and Magistris, 2008; Kezis et al., 1998; Michaelidou and Hassan, 2010; O'Donovan and McCarthy, 2002; Starr, 2009). These findings are not altogether surprising. Privileged consumers have more income to participate in upscale niche markets, and may have more exposure to stores selling ethical products, which are often located in affluent neighborhoods (Barnett et al., 2005a).

Economic privilege can facilitate access to ethical eating discourse, but there are also cultural elements shaping consumers' motivations (Brown et al., 2009). Sociologists, feminists and food scholars have long known that culture shapes food choices, and that food decision-making involves more than simple cost-benefit logic (for example, Bourdieu, 1984; DeVault, 1991). But how exactly does culture shape the process of ethical eating? One particularly significant response to this question is cultural capital. Purchasing products deemed 'ethical' is not simply an indicator of one's economic resources, but also relies on the possession of 'cultural capital', which involves high status cultural signals and internalized dispositions (Bourdieu, 1984). Food culture is heavily imbued with elements of cultural capital; 
it influences which foods are eaten, enjoyed and valued by difference social classes, which foods feel relatively uncomfortable and unfamiliar, and whether or not food is seen a significant venue for creative expression and the cultivation of an 'aesthetic disposition' (Bourdieu, 1984: 28). DeVault has argued that for 'families with more resources, food becomes an arena for self-expression... in poor families, feeding and eating themselves are themselves the achievement' (1991: 201). A significant component of contemporary foodie culture involves a specific element of cultural capital: knowledge of food politics, which involves appreciating what foods are politically correct and environmentally defensible (Johnston and Baumann, 2010: 127). Because cultural capital is one of the most important traits of the upper middle-class - class mobility is rendered remarkably difficult without it (Bourdieu, 1984; Lamont, 1992: 3) - ethical consumption can potentially work to naturalize or legitimate social inequality and class boundaries (see Cole, 2008).

Given the economic and cultural inequalities that characterize contemporary food culture, food scholars have reacted against a market-based dichotomy of 'privileged ethical eaters' versus 'marginalized unethical eaters' (see Adams and Raisborough, 2010: 258; Barnett et al., 2005a; Dolan, 2005; DuPuis and Goodman, 2005). As Guthman (2003) notes, we cannot assume that affluent shoppers display heightened reflexivity about social and environmental issues in the food system, even though they have more resources to participate in niche markets. Wealthy people may be more likely to buy ethical products, but it is not clear they will necessarily implement other ethical consumption practices that rely more on time than money (Star, 2009: 919). In fact, we know little about the extent to which consumers in different social groups consciously examine the ethics of their food choices while shopping, beyond simply buying products or articulating their support for issues (Auger et al., 2003: 285; Belcher et al., 2007; Beagan et al., 2010; Roberts, 1996). Standard survey research on ethical consumption is often limited in this respect; it measures opinions on ethical issues, but cannot always parse out whether behavior follows from attitudinal support, ${ }^{2}$ or how ethical issues conflict with other considerations such as convenience, price, and selection in daily shopping decisions (Adams and Raisborough, 2010: 259; Auger et al., 2003). Some scholars thus call for research that 'considers the processes of meaning construction amongst actual and potential consumers' (Weatherell et al., 2003: 243, emphasis ours), and contextualizes ethical consumption within the 'complexity of everyday life' (Adams and Raisborough, 2010: 257). While existing research suggests that class and cultural context play a role shaping ethical eating, more work is needed to examine how class and culture shape the meanings and practices of ethical consumption in everyday life. This is precisely what our paper seeks to address.

To better understand the meanings of ethical eating discourse for differentially privileged individuals, we take inspiration from cultural sociology and employ two interrelated tools well suited to analyzing culture, class, and inequality: cultural repertoires and symbolic boundaries. The concept of 'cultural repertoire' (Lamont, 1992; Swidler, 1986, 2001; Tilly, 1993) can help us avoid viewing 'ethical eating' as a monolithic force or 'given object' (Adams and Raisborough, 2010: 259), and 
instead appreciate how actors creatively employ select elements of this discourse in everyday life. Like a musical 'set' comprised of multiple songs, a cultural repertoire is composed of a varied set of understandings, thought habits, values, routines and ideas. Actors understand their actions by employing different elements of cultural repertoires; what they draw from depends on the situation, as well as their access to different repertoires (Lamont, 2000; Swidler, 1986: 277; Swidler, 2001). The cultural repertoire concept brings attention to how social agents selectively draw from elements of a larger culture to make sense of their decisions, or justify action and inaction. In this paper, we refer to an 'ethical eating repertoire' that involves a broad set of culinary practices, ideas, and habits. Rather than seeing ethical eating as a singular, static piece of culture, we want to underscore its multifaceted and dynamic nature. ${ }^{3}$ Through our interview data, we investigate what elements of an ethical eating repertoire appear most salient to our participants, and what themes are relatively minor. To be clear, we are not claiming that these themes are universally held. Not only do ethical eating repertoires differ geographically (see Bondy and Talwar, 2011; Sassatelli and Davolio, 2010), but they constantly evolve. Our findings emerged in a specific Canadian context and reflect the consumption practices of participants in a particular urban location at a given time (2008-2010).

A second, related cultural sociology concept that helps us unpack the phenomena of ethical eating is the concept of symbolic boundaries, which refer to the 'conceptual distinctions that we make to categorize objects, people, and practices' (Lamont, 1992: 9). Boundary work involves the subjective categories used to include and exclude people in conceptual maps, and describes a process where 'individuals define their identity in opposition to that of others by drawing symbolic boundaries' (Lamont, 1992: 233). Put simply, boundaries are drawn to distinguish oneself, but are also a sign of group membership. Scholarship on boundaries and group belonging has a long intellectual history (for example, Becker, 1963; Douglas, 1966; Durkheim and Mauss, 1963). Today, it is strongly associated with Michele Lamont's scholarship, particularly her qualitative interviews with upper middle class and working class men in the US and France (1992, 2000; see also Lamont and Fournier, 1992). Lamont's work convincingly demonstrates the significance of boundary work; boundaries can be inclusive, but they also 'potentially produce inequality because they are an essential medium through which individuals acquire status, monopolize resources, ward off threats, or legitimate their social advances, often in reference to superior lifestyle, habits, character, or competences' (Lamont, 1992: 12).

The analysis of boundaries drawn by interviewees ${ }^{4}$ can generate understanding of how boundary work differs across social categories such as class and gender (Lamont, 1992: 6). Lamont distinguishes three kinds of symbolic boundaries: socioeconomic, cultural and moral (1992: 4). In the case of ethical eating, cultural and moral boundaries are particularly relevant. ${ }^{5}$ Cultural boundaries are 'drawn on the basis of education, intelligence, manners, tastes and command of high culture', while moral boundaries are 'drawn on the basis of moral character' 
(Lamont, 1992: 4). Lamont's (1992) interviews with working class and uppermiddle class Americans revealed that moral boundaries were not a secondary consideration - as implied by Bourdieu's seminal work on cultural distinction which prioritizes cultural boundaries (1984) - but were often central to how individuals understood themselves and their relationship to others. Extending these cultural sociology concepts to the case of ethical eating, we seek to better understand the relevance of symbolic boundary work involving food choices. We investigate how ethical eating repertoires may be used to draw cultural and moral boundaries that provide a sense of distinction and differentiation from others.

\section{Data and methods}

This study was conducted as part of a multi-site study, the original purpose of which was to examine how local food cultures, socioeconomic status, and the family context interact to produce the everyday food practices of families in different Canadian communities. The communities that are the focus of the present paper are two neighborhoods in the city of Toronto: South Parkdale and North Riverdale. Data collection took place from 2008 to 2010 and families were recruited through neighborhood advertising and word of mouth. We did not endeavor to specifically recruit ethically engaged families. In each neighborhood we interviewed ten families, and in each family we interviewed at least one parent and one teenager (aged 13-19 years). We had two interviews with each family member. The first interview asked a range of questions about the family's food habits, and included specific questions about ethical eating. The second interview involved a photo sort where we discussed participants' thoughts about food photos that they had taken and their reactions to several pre-chosen food images. The interview transcripts were transcribed and then coded using Atlas.Ti.

The families involved in this project were quite diverse (see Appendix Table 1). Participant incomes ranged widely. Eleven of the 20 families had incomes below CAD $\$ 50,000$, two had an income of between $\$ 50,000$ and $\$ 100,000$ and seven had incomes above $\$ 100,000$. The ethno-racial background of participants was also diverse. Fourteen families were Caucasian, three were from racialized groups (Tibetan and Eritrean), and three were of mixed race (two Black/Caucasian and one Japanese/Caucasian). Eleven families included one or more parent with a university education. In each site, we also evaluated the social class status of participants, which we determined based primarily on occupation, since this characteristic usefully combines education, income, and occupational prestige (Gilbert, 2008; Goldthorpe, 1987; Lamont, 1992). Seven families were designated as upper-middle class, eight were lower-middle class and five were working class or working poor (see Appendix Table 1 for a summary of demographic information).

We began data analysis by looking to see how participants themselves understood and discussed 'ethical eating' - especially in response to questions about the influence of 'ethical issues' on their eating practices. From this initial reading, it became clear that many interviewees were drawing from a common ethical eating 
repertoire with recognizable themes. We then dialectically considered the interviewees' own descriptions of ethical eating and the larger discursive and theoretical context of ethical eating discourse (Burawoy, 2009). To operationalize the idea of a dominant, or hegemonic ethical eating repertoire, we drew from Johnston and Baumann's work (2010) documenting three prominent thematic clusters in North American ethical eating discourse - local provenance and seasonality, organics and sustainability, animal welfare - and one minor, thematic cluster concerning social justice, labor issues and community development (2010: 138-163). After observing the ubiquity of these thematic clusters in our interview data, we decided to use these major and minor thematic categories to conceptualize a dominant ethical eating repertoire that our participants drew from in varying degrees. We also noted instances in our data where interviewees spoke about how other moral concerns - those not typically captured in the dominant ethical eating discourse documented by previous research - influenced their food practices. We developed another set of codes for these concerns and used these codes to capture relevant practices and thinking.

We categorized interview transcripts according to the relative presence/absence of prevailing ethical consumption themes. In keeping with the concept of a cultural repertoire, we made note of interviewee food practices (for example, routines, habits) as well as their ideas, knowledge, and awareness of the food system more generally. Knowledge of ethical eating referred to participants expressing general awareness of key ideas, debates, and aspirations related to dominant forms of ethical consumption (for example, understanding that eating locally is thought to reduce carbon emissions). Practices included activities undertaken by participants that reflected key elements of the dominant ethical eating repertoire (for example, buying local food to reduce carbon emissions, avoiding heavily packaged foods). Based on a systematic examination of family ideas and practices, families were coded as to whether they had 'weak', 'moderate', or 'strong' levels of engagement with the dominant ethical eating repertoire. 'Weak' engagement was indicated by a very minimal presence of the cultural repertoire in the interviews, either in knowledge or practice. Families that were 'moderately' engaged drew on some key themes of ethical eating, but there was some tension in the engagement - for example, only a few themes were mentioned, or there was significant knowledge, but only minimal practice. We coded families as 'strongly' engaged when we observed significant evidence of knowledge and practices associated with the dominant ethical eating repertoire. In general, our interview data revealed that engagement was broadly dispersed. Of our 20 families, eight were weakly engaged, six moderately engaged, and six highly engaged. It is worth briefly noting that most of the families who were strongly engaged with the dominant ethical eating repertoire were upper middle class (4/6) and most of the moderately engaged families were lower middle class (4/ $6)$. Half of the weakly engaged families were working class/working poor (4/8), and the remaining weakly engaged families were upper middle class $(2 / 8)$ and lower middle class (2/8) (see Appendix Table 2 for summary of class engagement distinctions). 
Next, we explore major themes within the dominant ethical eating repertoire, how participants of different classes and ethno-cultural backgrounds drew from this repertoire, and the nuances and contradictions that emerged in these engagements.

\section{Ethical eating in everyday life}

In this section, we document what ethical eating looked like in the lives of our participants. First, we describe to what extent the dominant ethical eating repertoire was recognized and understood by participants - what ideas and practices were emphasized and minimized, and what tensions were observed. Second, we analyze who appeared to have the greatest access to ethical eating repertoires, and which participants seemed relatively marginalized. Third, we address some of the moral quandaries articulated by marginalized eaters, and demonstrate the boundary work these groups carried out to maintain their dignities around food choice.

\section{The dominant ethical eating repertoire: Major and minor elements}

Here we illustrate prominent elements observed in ethical eating repertoires eco-eating (local and organic) and limiting meat - as well as more minor elements concerned with community-building and creating relationships with producers and retailers.

Eco-eating: Local and organic. As with other work on ethical consumption (Johnston and Bauman, 2010: 160), our interviews revealed that environmental considerations were a predominant element of ethical eating repertoires. For many people, ethical eating was synonymous with 'green' eating, ${ }^{6}$ which was primarily understood as involving local and/or organic foods. Connections between food choices and environmental damage were frequently discussed in our interviews, such as carbon emissions from food transport, and the harmful effects of pesticides and factory farming. Environmental themes were commonly referenced in relation to organic and local food, as well as vegetarianism or reduced meat consumption. For example, when asked about whether anyone in the family thinks about ethical issues when buying food, Claude, a white upper-middle class teenager reflected: 'We try to stay organic whenever we can and local definitely for fruits and stuff. We try to stay with what's in season and what's from Canada, from Ontario... Organic, less pesticide, and stuff on it and local stuff's usually more fresh, and environmentally hasn't been brought that far. So, less fuel spent on one peach.' As Claude's words make clear, both organic and local food consumption were linked to environmental sustainability. In addition, another key part of the ethical eating repertoire in our sample involved understanding, and engaging with the tension between organic foods (grown without damaging pesticides, herbicides, and fertilizers) and locally grown foods (which travel a shorter distance from field to plate). Ted, a white lower-middle class father indicated his awareness of this, as 
well as the imperatives of the ' 100 mile diet': 'Well, like I said before, I'll buy organic. I'll buy local over California organics and I try to keep things that are close to that one hundred mile radius. I try to buy local as much as I can. And if I can't I will buy organic, but I try to buy Canadian produce.'

While local and organic foods were central to ethical eating repertoires, another prominent topic in these discussions involved cost concerns, and these concerns shaped how ethical eating was actually carried out in daily food practices. ${ }^{7}$ Concerns about the price of organic and local foods was something observed at all income levels, with only one upper-middle class family talking about purchasing organic meat and dairy exclusively. Bojana, a low-income, lower-middle class mother noted: 'I would love to be able to support local producers and organic producers much more than I can.' Wendy, a low-income woman living in subsidized housing with her grandson said, 'I'd like to buy more stuff that's grown in Ontario closer to home... I don't know why we can't have more of that... instead of having to have stuff imported from California and Mexico.'

Concern about the cost of local and organic foods was often accompanied by skepticism about the health and environmental claims of these foods. Marina, a white upper-middle class mother went so far as to frame shoppers as being duped into high prices for organic food - prices she said were not an option for her family:

Something I haven't talked about is organic food, which we're not into. Mostly because it's so expensive. Most of my friends do eat organic food and they shop at the Big Carrot [a local health food store]. I don't, just because we can't afford it. It's funny to consider how a husband and wife influence each other. My husband thinks [organic food] is BS. And I'm not sure. I'm not going to spend money that way ... If the price of organic food came down significantly and it was side by side with the alternative in the grocery store and the price was the same I would buy organic food.

While some participants rejected organic food outright as too pricey, other participants talked about strategies for eating 'ethically' on a budget, such as buying either local or organic, growing their own food, buying smaller quantities of local or organic products, and shopping at stores that carry alternatives to certified products such as antibiotic-free meat. Krista, the mother in another white upper-middle class family, described these cheaper kinds of foods 'as good as organic but not officially organic'.

Restricting meat. Another prominent element of ethical eating repertoires in our interviews was the idea of limiting meat consumption. Several participants had been vegetarians in the past, some were currently vegetarians, and some made a point of eating little meat. While participants spoke about restricting meat for health reasons, they also discussed the effects of the meat industry on the environment, and criticized factory farming and animal mistreatment more generally. Dina, a white upper-middle-class participant, explained why she limits her meat 
consumption and buys organic or free-range meat, and her explanation touches on all of these reasons:

\begin{abstract}
We don't need to eat that much meat for starters [for health reasons], but when we do I want it to be really good ...I think all the reasons that people have for not eating meat or preferring free-range as opposed to you know factory, I think they are all valid ... If I think about the animal welfare, I'm like, yeah that's terrible. You know this [free-range and/or organic meat] is a much better option. Or if I think about the manner in which they are processed ...I think this [free-range and/or organic meat] is much [better]. And from an environmental point of view, probably especially for bigger animals like cows and stuff, that [point of view] would be the one I would put the most emphasis, the most importance on ... you know, smaller farms, better life for the animals. They're better looked after, the quality [of the meat] is going to be better.
\end{abstract}

Marianne, a lower-middle-class mother of mixed ethno-racial background who was very strongly engaged with ethical eating repertoires, connected her reduced meat consumption to global hunger: 'I'm trying to do my part, you know, eating less meat. We hardly eat meat...I read again somewhere, I read a lot, that if we reduced our meat consumption by ten percent we'd have enough grain left over to feed every hungry person in the world. And ten percent isn't much.' This type of global concern was rare in our sample, and was only mentioned by one other participant, Emma, a teenager of mixed Japanese-Caucasian ancestry from a lower-middle class family. One of her reasons for being vegetarian was her concern about 'the factory farming stuff and how the amount of grain that goes to feed the cows could feed the entire world population'. There were some Buddhists in our sample, whose reasons for being vegetarian differed markedly from other participants, and we explore these issues below.

Social connections and community building. A final element of ethical eating repertoires clustered around the idea of enhancing social connections and building community. As per other findings on food politics (Johnston and Baumann, 2010), social factors were mentioned less frequently than environmental motivations, and were most commonly framed through a local lens rather than linked to global inequality or poverty (even though ethical consumption is commonly linked to a concern for distant others; see Barnett et al., 2005b). For example, some participants talked about wanting to support businesses and economic development in their local community. The most common way this was articulated was through support for local farmers' markets. Nine of 20 families described attending farmers' markets; higher-class participants mentioned attending farmers' markets with greater regularity, although some lower-class participants noted that they would shop at markets if they could afford to. Another related way that participants showed concern about community building was through a preference for small, local businesses, and building relationships with local retailers. Ted, a father from a 
white lower-middle class family spoke positively about his routine of shopping at small local retailers, even though he has access to several large supermarkets. Summer, a white upper-middle-class teenager talked about the importance of her dad's relationship with their local butcher: 'We have this one butcher and my dad knows him really well... [he] gets free bones from this guy.' Her mother Dina talked in more detail about the value of this kind of relationship: 'I think this is much more fun shopping than the supermarket. And, you know, you talk to the people who make the stuff or grow it and bring it. . So I think it's nice. I think I like knowing the people. You know, I think there's something about that that's worthwhile.' Other participants mentioned wanting to 'keep the money in the [local] economy', feeling more trust in local business people and being able to find out more details about products than in a regular supermarket.

In a few instances, participants expressed concern about fair wages and working conditions for workers, both domestically and abroad. Marianne, who was strongly engaged with the dominant ethical consumption repertoire, described her reasons for patronizing local businesses as follows:

I'd rather support a small business person who's trying to keep their family together than some corporation that's making billions. And you don't really know where some of the stuff's coming from sometimes. And I just know that workers say, in Mexico, aren't being paid as good a wage ...I paid more for tomatoes coming from Ontario than I did for Mexican tomatoes and I didn't mind, I just didn't buy as many as I might have bought.

In summary, in speaking about 'ethical eating', many of our participants drew on a dominant North American ethical eating repertoire that emphasize 'green' food choices (for example, organic, local), humane animal husbandry, and pay some attention to social issues, especially supporting local growers and retailers. However, participant awareness of these repertoires was not a guarantee of engagement with them, as will be demonstrated in the following section.

\section{Dominant ethical eating repertoires: High engagement and marginalization}

In this section, we provide examples that demonstrate the range of engagement with dominant ethical eating repertoires, and talk more specifically about which groups appear most engaged with dominant repertoires. Participants who were highly engaged with the dominant ethical eating repertoire were all middle class (mainly upper-middle but also lower-middle) and were predominantly white (only one highly engaged family was not white but was of mixed white, middle eastern and black background). In the white families that had both a high income and high education level, we observed engagement with all elements of the ethical eating repertoire at the level of theory and practice, meaning that the interviewees were both familiar with these ideas, and incorporated them significantly into their food practices. For example, Dina's family, a white, upper-middle class family, buys a 
good deal of local, organic and free-range products. They concern themselves with health, environmental, and animal welfare issues related to factory farming (for example, over-fishing, water contamination from factory farm run-off). They enjoy buying seasonally from farmers' markets, and find meaning in getting to know local food store owners. The daughter in this family was only 12 years old, but was highly knowledgeable about ethical eating issues, and spoke in impressive detail about topics such as the practice of feeding corn to cows who are 'supposed to eat grass'. Both mother and daughter spoke with pride and enthusiasm about the family's cooking and food shopping habits; Dina's eyes lit up when she described how she is 'inspired' to cook by the 'lovely' shapes and colors of food items at a favorite farmers' market. Krista's family also exemplified high engagement. She is a high school teacher and teaches a unit on food studies. As such, she is keenly aware of food system issues and expressed considerable concerns about the environmental repercussions of food packaging and waste. Her family purchases food at farmers' markets during the harvest seasons (which Krista 'really savors'), and also purchases 'organic-quality' meat at a Mennonite store. Krista described being a vegetarian on and off throughout her adulthood, and how she currently endeavors to eat low on the food chain. Her daughter Ruth is a vegetarian, which she attributed to being exposed to people who educated her about social justice issues.

Our data suggest that privileged populations may be better positioned to engage with the dominant ethical eating repertoire. Four out of the six families that were highly engaged had high education and high income (and were upper-middle class), and all of the six highly engaged families had high levels of education. Significantly, one family with a low income but high education was strongly engaged with ethical eating repertoires. ${ }^{8}$ The working poor families we interviewed were less likely to engage with the cultural repertoire of ethical consumption. In fact, all of these families had low engagement with the dominant ethical eating repertoire. The racialized immigrant families were also less likely to engage with themes in the ethical eating repertoire. Of the four racialized immigrant families in our sample, three had low engagement with the ethical eating repertoire, and one had moderate engagement. However, this does not mean that having a high income, or middle class status or being from a white background guaranteed a strong engagement with the dominant ethical eating repertoire. There were a number of white families with high incomes and/or high class status who were moderately or weakly engaged with the dominant ethical eating repertoire.

The connection between privilege and ethical eating repertoires in our data raises the following question about boundaries: Did the highly engaged families use ethical consumption repertoires to draw moral boundaries demarcating themselves as 'good' eaters who are morally superior to others? Confirming other scholarship on ethical consumption and moral boundaries (Brown, 2009; Jabs et al., 1998; Stiles, 1998), our interviews suggest that moral boundaries are not necessarily drawn through ethical consumption. Ethical food choices certainly were part of what some privileged families found 'good' about their eating (for example, buying local or organic foods), but among our 47 participants, only one seemed to draw 
deliberate moral boundaries between himself and others whom he saw as not consuming ethically. This participant, a lower-middle class teenager, was very conscious and knowledgeable about, as he put it, 'where food comes from' (for example, the work that farmers and food industry workers put into food before it gets to the consumer and the material and chemical processes involved). At a few points in the interviews, he criticized his school peers and 'other people in Toronto' for what he saw as a lack of consciousness around food - for not knowing about 'the effects of something as basic as food on their bodies and on the world'. However, this participant was unusual in our sample. Our other participants in white lower-middle and upper-middle class families were more likely to use cultural boundaries to construct an image of 'good' and 'bad' eating in general (not only based on ethical eating discourses) that provided a sense of distinction. ${ }^{9}$ These privileged families commonly defined their own eating practices as 'good' by referencing their familiarity with quality foods (for example, boutique olive oil, Berkshire pork) and health-promoting foods (for example, low-fat, high-fiber foods). For example, Ivana, the mother in a white upper-middle class family, had little to say about ethical eating, but spoke at length about eating healthy, and home-cooked meals that were low in fat and sodium. In an exchange that revealed a great deal about Ivana's understanding of 'good', respectable eating, she stated that dessert 'might be a treat on the weekend for Sunday dinner', but she doesn't normally keep it in the house. During the interview she appeared deeply embarrassed when her husband entered the kitchen and served himself some ice cream from one of several tubs that were in the freezer. In contrast to Ivana's family, Jane and Don's family, another white upper-middle class family, did engage strongly with the dominant ethical eating repertoire, but like Ivana's family, they also framed their eating habits as 'good' through talk of high quality, healthy foods. Though perhaps not intentionally (nor maliciously), they drew clear cultural boundaries in their discussion of the way Don's family ate when he was growing up in a 'lunch bucket town'. The couple laughed heartily as Don described the 'abysmal' foods he ate as a kid such as baloney sandwiches with ketchup, and Jell-O salads with marshmallows. In a separate interview, Don and Jane's daughters, Adelle and Rosemarie, also criticized the food habits of Don's family, saying that they would 'make fun of' these relatives because of their marshmallow salads and love of 'meat and potatoes'. In our sample as a whole, it was through talk of food quality and healthfulness where cultural boundaries were most strongly drawn by white middle class families between themselves as 'good' eaters and others as 'bad' eaters.

In sum, our interviews suggest that class status and income enable strong engagement with the dominant ethical eating repertoire, but that these factors are no guarantee of engagement. In the case of lower- and upper-middle class families, the dominant ethical eating repertoire (for example, organic, local) was used to construct one's eating practices as 'good', but more salient cultural boundaries were drawn around foods associated with healthy eating and 'gourmet' ingredients. 


\section{Eating and symbolic boundary work in marginalized communities}

While many of the low income and racialized families in our sample were weakly or moderately engaged with the dominant ethical eating repertoire (for example, they bought less organic food or knew less about the 'buy local' philosophy), we want to make clear that these families cannot be said to be 'unethical' eaters in a general sense. Not only is this assertion politically problematic, but it is empirically suspect - many of these families showed significant attention to moral dilemmas and issues related to food. However, these participants tended to draw from cultural repertoires that deviated from, or fell outside the dominant ethical eating repertoire. In this section, our findings line up with Lamont's work (1992) on symbolic boundaries and the ways marginalized groups draw upon different cultural repertoires to carry out boundary work and maintain their dignities.

We observed two patterns among participants who appeared marginalized from the dominant ethical eating repertoire that suggest significant symbolic boundary work through food choice. In the first instance, which we term 'creative adaptation of the dominant ethical eating repertoire', participants re-thought ethical eating practices to fit their material circumstances. We observed creative adaptation in families who demonstrated consciousness of key tenets of ethical eating discourse such as environmental concerns from wasteful packaging and overconsumption, but whose access to 'ethical food' through the market was limited because of their low incomes. Some of these families focused less on what they bought and instead presented evidence of their ethical standing via waste reduction and recycling. Linda, a single mother with a low income specifically stated that she cares about 'ethical things' but that she just can't afford to buy organic or fair trade foods. She described how she will eat organic food if it is available from her local food bank, or if it is on sale for a very low price. Unable to fully participate in the ethical eating repertoire through shopping, both she and her daughter Sasha focused on how they are conscientious about disposing of food packaging and try to produce little waste. Sasha said that she takes care to recycle, and Linda mentioned that she uses a Brita filter instead of water bottles, and milk bags instead of jugs. As a single mother who does not work and who accesses the food bank program in her subsidized apartment complex, Linda talked about saving money by buying products from the bulk food store, and argued that she doesn't need to worry about the waste or environmental cost that is associated with heavily packaged or processed food products. Rather than understand her low income as a personal failing, both Linda and her daughter framed the family's minimal consumption as a way to demonstrate care and concern for the environment.

Another low-income teenager, Alberto, also drew symbolic boundaries that positioned his low-income food practices as ethically defensible. When asked about eating habits in his neighborhood of Parkdale, he mentioned that many of his neighbors have a low income and 'have less money to spend so they got to make it last'. He contrasted the grocery shopping practices of suburban car owners who 'just fill up their cart. . . with like a hundred dollars worth of stuff' with those of city 
dwellers of modest means like himself and his grandmother who don't own a car, have to 'be more selective in what they really need' and 'lug' food home on foot even 'in the snow and wintertime'. Interestingly, although this contrast at first seems to be one where the lower income group is disadvantaged, as Alberto continues, we see how he begins to turn the comparison around:

People are out in the suburbs where they drive to like a Dominion or a Sobey's. And just fill up their cart. They don't have to walk ... I don't think they're really concerned about what's going on out, like out around them. Cause you see them with all the plastic bags and everything. So I don't know if they're that concerned about the environment ... Like I recycle and I don't get a lot of plastic bags ... [And we carry our groceries home] in a box. It's like a luggage cart.

In Alberto's formulation, practices that may be brought on by poverty (for example, minimal consumption) are reframed as ethical practices that benefit the environment. A moral boundary is drawn distinguishing his behavior as conscientious and not wasteful compared with wealthy suburban shoppers, and defending the moral intentions of low-income urbanites.

Patricia's family, who also live on a low income, similarly demonstrated a creative adaptation of cultural repertoires to fit material constraints and demonstrate ethical eating. In this case, the moral boundary work also concerned the issue of food waste and careful consumption. Patricia was clear to present herself as somebody who is not wasteful, and expressed a serious concern with not throwing foods away needlessly. She described how she goes to great lengths to create meals from foods soon to reach their expiry date. This resulted in some interesting combinations of food, including a dinner that she described as a 'leftover Kraft dinner stirfry with rapini and chili sauce'. As a single parent, her food choices are shaped by the reduced income that resulted from the breakup of her marriage, and concerns about being unable to afford food are omnipresent for her. She talked about her 'frugalness' and 'not being wasteful' as indicative of the fact that she values sustainability 'on a day-to-day living kind of basis'.

A second way symbolic boundary work was carried out in marginalized communities was by drawing on different cultural repertoires to engage with moral concerns around eating. These participants can be distinguished from the 'creative adapters' above because they drew little on elements of the dominant ethical eating repertoire (for example, environmental concerns) to talk about moral issues around their eating, and rather framed these issues in terms of other ethical frameworks. While our sample is not large enough for us to establish the origins of these other cultural repertoires, there is evidence that they may be based in ethno-cultural or class traditions, or even personal philosophical orientations. This was most evident in the case of religious vegetarians. The two Tibetan families in our sample drew upon cultural and religious discourses when describing their moral relationship to eating animals. Although many Euro-Canadian participants also spoke about restricting meat consumption, the discourses these families drew upon differed 
markedly from the Tibetans. Most Euro-Canadians spoke about health benefits, environmental impact, or the mistreatment of animals in confined livestock operations, while the morality of killing or eating an animal was not explicitly discussed. ${ }^{10}$ For our Tibetan participants, being conscious about eating meat was not explicitly about health, the environment or industrial livestock practices, but about culture, religion and one's fundamental relationship to living beings. For instance, Lasya, a Tibetan mother of three boys (one of which is a Buddhist monk in India), spoke of her growing desire to eat less meat as she gets older because 'when you grow older you start thinking more about a religious point of view'. Her family is not completely vegetarian, but she serves meat in very specific ways, such as only eating one kind of meat at a time. When asked about how these practices connect to religion, she explained that Buddhists try not to eat small animals such as shrimp, or more than one type of meat per meal. As she puts it: 'We consider [it] as a $\sin$. . . because [it means] eating so many life [sic] at one time.' For Shamar, her 15-year-old son, being vegetarian was also clearly about ethno-cultural identity. When asked why he had at one point tried to be a vegetarian, his response was: 'I'm Tibetan and we are supposed to, you're not supposed to really eat animals.' Shamar's motivations to become a vegetarian revolved less around health or environmental concerns, as was the case for many other participants, and more around his Tibetan and Buddhist identity.

The other Tibetan woman in our sample, Pema, a mother of a daughter and a son (who also lives in India as a Buddhist monk), adhered more strictly to Buddhist teachings about vegetarianism. Although she prepared meat for her husband and daughter, who wanted to eat meat, she herself was completely vegetarian. She described a pivotal experience driving past a local butcher in India where she said she thought: 'Here somebody's crying.' When describing the scene, she herself began to cry, and said: 'There are some animals, maybe they are crying for help but we are enjoying the meat, you know, when we eat meat. That time we enjoy it, we don't feel like how much... maybe it's hurting him. Then I thought, no it's not a good idea to eat meat.' Non-Tibetan participants also spoke about animal suffering and cruelty, as we saw above, but as we see here, the Tibetan families more explicitly invoked the intrinsic value of animals' lives. Pema's use of the pronouns 'him', 'he', and 'somebody' when referring to animals (rather than 'it' or 'something') establishes animals as equals to be addressed in the same way as humans. ${ }^{11}$ There was little evidence of these fluid boundaries between animals and humans in other interviews.

In a handful of cases, participants connected their food practices with moral issues of poverty and food scarcity in their neighborhood. Interestingly, this connection was only made by participants who themselves had low incomes or had themselves used food banks. For example, Kim, a single mother with a low income, spoke about patronizing a local café because it hires at-risk youth so that they can 'learn some life skills, employability skills'. Robin, a 58-year-old Parkdale resident living on social assistance, spoke about the benefits of having social organizations in the neighborhood offering free lunches and sometimes dinners 'cause there's a lot 
of people that need them'. Bojana was particularly aspirational about good food and health being a right for every community. A low-income woman herself, she volunteers a significant amount of time in community gardens, and argued:

If you eat properly, you feel better, your brain works better. I really [spend my life] spreading this knowledge but also offering. I would like if every community has a community kitchen that serves good food - healthy, homemade food. A huge number of people use these food banks but that's not very good food. It's just to fill their stomach, nothing more than that. People don't have their vitality and their brain kind of goes down. That's what I see teenagers go through.

Some of our lower income and racialized participants also performed moral boundary work around food when they described their involvement in the eating practices of elderly neighbors or acquaintances. These participants expressed concern that seniors with few family ties in the city may sometimes not be able to enjoy healthful or delicious food. By addressing this situation, they saw themselves as promoting a social good, even if they described these efforts in modest terms. Robin spoke about her volunteer work with seniors in her neighborhood, the inadequacy of seniors' food access, and her efforts to get them higher quality food than they normally have access to. While Robin appeared food insecure herself, she mentioned inviting 'two elderly men who live alone' to her home for Christmas dinner, 'cause they have no family and that'. Lasya, a 45-year-old Tibetan immigrant with a low income, also spoke of her involvement in the food lives of seniors, and mentioned going grocery shopping once a week for some elderly acquaintances. Interestingly, when asked about whether their eating practices were influenced by ethical issues, neither woman brought up her involvement with seniors. By tending to the food needs of the elderly, these women did not draw upon the dominant ethical eating repertoire, but instead drew from other cultural tools that shape their self-conception as 'moral', caring people. In the case of Lasya, it is possible that she is drawing upon ethno-cultural discourses about the importance of respecting elders; Pema, the other Tibetan mother we spoke to, described the cultural value placed on 'respect[ing] our elders' when describing the Tibetan tradition of serving food to elder family members first.

Besides her concern about seniors' diets, Robin displayed further moral boundary work by defending the eating practices of racialized immigrants in her community. Although she herself is Caucasian and Canadian-born, after having been married to an Ethiopian man and working in a medical office where patients were mainly immigrants of color, she described noticing 'racist' comments on the part of Caucasian friends and acquaintances. When she adopted immigrant eating styles, such comments were sometimes directed at her. She described the situation this way: 'When I first started going out with a lot of Muslim people and eating with them it became such a habit for me to use my hands and sometimes I'd forget myself and I'd be at home, and my boyfriend would say: "I hate it so much that you eat with your hands. It's so goddamn piggish." Yet rather than go back to her 
earlier eating habits, she maintained her new habits and spoke with fondness about the new foods and food practices: 'I really got to know a lot of different foods and foods that I liked. I mean I'd never heard of rice and chickpeas wrapped in grape leaves. You know and then when I had them [I thought] "Oh this is pretty good."' Not only did Robin enjoy these foods, but she was eager to defend newcomers' rights to maintain not only culinary but other cultural practices:

Not until I did start working with a lot of immigrant people and it's my Canadian friends who would say, 'Oh look that they're dressed in their pajamas' or 'Look at those people eating with their hands' or 'Look at that one with his hair wrapped up'. They're just people leave them alone. You know they come from a different background, a different country. They're entitled to their own ways. I'm sure to us that we look to them, we probably look naked half the time you know?

In short, while Robin was only weakly engaged with the dominant ethical eating repertoires, she still articulated moral boundaries around food habits. This happened not through specific ethical food purchases but through embracing and defending culinary and cultural diversity - a practice that she framed as distinct from her xenophobic friends and family members. Again, participants in this last group did not draw from the dominant ethical eating repertoire to frame food practices that clearly had a significant moral motivation. Rather, they seemed to be drawing from ethno-cultural, class, or perhaps even personal ideas about 'doing good'.

\section{Conclusions}

If we accept that shopping and eating to 'make a difference' represent an important way that individuals try to address social and environmental problems, it seems important to better understand how different groups engage with this practice. Our study revealed how people in varied class positions and with varied racial-ethnic backgrounds understand and perform ethical eating. While ethical eating makes up a broad social discourse with multiple framings, our interview data allowed us to draw out patterns and make tentative conclusions about the ways ethical eating repertoires are employed in daily food practices.

First, we found that economic and cultural privilege does seem to facilitate access to a dominant ethical eating repertoire. Participants from marginalized socio-demographic and ethnic backgrounds appeared to have less access to this repertoire, although this does not mean that they are necessarily unethical in their consumption practices. By and large, the people in our study who displayed knowledge and practices associated with the dominant ethical eating repertoire were white and lower- or upper-middle class. While cultural and economic privilege (for example, having a white Euro-Canadian background, middle class status and a high income) enabled access to the dominant ethical eating repertoire, it did not guarantee strong engagement for our participants, nor was it necessary 
for strong engagement. This point was convincingly demonstrated by the existence in our sample of lower- and upper-middle class people (many with high incomes) who were only weakly engaged with the dominant ethical consumption repertoire, as well as one low-income family who was strongly engaged. Nevertheless, privileged participants constructed cultural boundaries that allowed them to present their eating practices as 'good' (for example, centered on healthy, high quality foods), even when they were not strongly engaged in the dominant ethical eating discourse. The importance of food quality and healthfulness in the talk of many of our upper-middle class participants also displayed how they positioned themselves in relation to other people. While the sentiment, 'I eat ethically therefore I am better than people who don't' was rarely apparent in our interviews, the idea of healthful, high-quality foods providing a sense of cultural distinction, or status, was observed. This finding is in keeping with those of Lamont $(1992,2000)$, who found that higher class people draw symbolic boundaries based on cultural distinctions more than lower class people because they have more cultural capital.

In addition, we found that while the marginalized groups engaged less with the dominant ethical eating repertoire, this does not mean that they were necessarily unconcerned with the moral quandaries surrounding food choices. We provide data that help de-center a simplistic, market-driven understanding of ethical eating that equates 'ethics' with market access to ethical consumer markets (for example, organic, fair trade) - a conceptualization that posits low-income eaters as morally disengaged eaters. On the contrary, the moral boundaries drawn by less privileged groups demonstrated creative adaptation of dominant ethical eating repertoires to fit low-income circumstances as well as alternate cultural repertoires. Participants drew on the particular ethical eating repertoires to which they had access and which required less economic and cultural capital, perhaps because they have less access to other repertoires or forms of cultural capital. Our research thus adds empirical weight to Guthman's $(2003,2008)$ refutation of the notion that lower class and racialized people do not know about, care about or engage with moral issues surrounding eating. This is an important contribution given not only the history of marginalized groups being charged with moral deficiencies (Schwartz, 2000), but the tendency for market research to straightforwardly link ethical consumption with high-income consumption practices.

Our findings also point to the research possibilities of using in-depth qualitative interviews to better explore the relationship between abstract commitments to ethical eating and everyday food practices. As a method of producing and transmitting meaning, interviews allow for the possibility of new or unexpected insights into ethical consumption. By conducting a qualitative study where respondents described eating styles and practices in great detail, we were able to better understand the links between privilege and ethical eating, discover new and unexpected ways that less privileged people drew moral boundaries around food, and generate insights into the symbolic boundaries created and maintained through food choices in different class and ethno-cultural contexts. This study contributes to the emerging body of research in the qualitative tradition that illuminates the details of 
ethical consumption in lived experience (for example, Cherrier, 2005; Clavin and Lewis, 2005; Newholm, 2005).

\section{Notes}

1. Smith and Morton (2009) suggest that lower income people value products such as organic foods, but feel limited by lack of access to these foods and the high price point. A field experiment conducted by van Kempen et al. (2009) on rural Guatemalans also suggests that impoverished populations are not necessarily unethical, or unconcerned about the environment.

2. Some research suggests that stating one's support for ethical consumption does not necessarily translate into ethical consumption buying practices (Auger and Devinney, 2007; Devinney et al., 2006; Starr, 2009: 923).

3. Tilly emphasizes that repertoires 'do not descend from abstract philosophy or take shape as a result of political propaganda; they emerge from struggle' (1993: 264). While the origins of ethical eating repertoires cannot be explored here, Tilly's words draw attention to how social struggles for sustainable and non-exploitative food practices are part of a larger context shaping ethical eating repertoires.

4. Brown (2009) makes the important point that boundary work needs to be studied in naturalistic ethnographic contexts; however, we believe this does not negate the benefits of also studying how boundaries are drawn in interview settings.

5. Socioeconomic boundaries are based on judgments concerning 'wealth, power, or professional prestige' (Lamont, 1992: 4), and are less relevant to our analysis of ethical eating.

6. An interesting contrast to this finding can be found in Adams and Raisborough (2010), which documents how fair trade is a prominent element in British understandings of ethical consumption.

7. In their study of British consumers, Adams and Raisborough (2010: 263) also found that cost was a significant obstacle to 'being good' consumers.

8. It should be noted that while this family had a very low income, they were not lower class. The mother's college education in an environment-related field no doubt had an influence on her and her children's knowledge and practice of the dominant ethical eating repertoire.

9. Given previous work on class and cultural boundaries, this is not surprising. As Lamont's (1992) work suggests, higher classes use their cultural capital - their 'education, intelligence, manners, tastes and command of high culture' - to draw cultural boundaries (Bourdieu, 1986; Lamont, 1992: 4).

10. This finding fits with analyses of discourses surrounding meat reduction in foodie culture, which tends to not focus on debates around the morality of eating animals (see Johnston and Baumann, 2010: 154-160).

11. Although English is not Pema's first language, it was clear from the rest of the interview that her use of these pronouns in this way was not a grammatical error. (She used pronouns correctly in the rest of the interview.)

12. This is based on the family member with the highest level of education.

13. This category refers to families where at least one member identified as either 'fully' or 'partly' Tibetan, Eritrean, Japanese, Barbadian or Middle Eastern. We do not wish to imply that Caucasians cannot also be of mixed heritage (e.g. Irish/Scottish/British). 
14. Class designations were primarily based on occupation, since this characteristic usefully combines education, income, and occupational prestige (Gilbert, 2008; Goldthorpe, 1987; Lamont, 1992). When couples in a family might have been determined to have different class backgrounds, we used the partner with the higher class determination to establish the class of the household. When immigrant families were underemployed (e.g., trained for a professional job, but working in a working class job), we placed them in the class category that corresponds to the occupation they were trained in. Upper-middle class participants were those in professional or managerial jobs. The lower-middle class category included lower-level managers and administrators, lower-status white collar and some highly skilled blue collar workers. The working class/working poor/underclass category included those in low-skill manual and clerical jobs, as well as those with precarious work conditions.

\section{References}

Adams M and Raisborough J (2010) Making a difference: Ethical consumption and the everyday. British Journal of Sociology 61(2): 256-274.

Alatas SH (1977) The Myth of the Lazy Native. New York: Routledge.

Aldanondo-Oachoa AM and Almansa-Saez C (2009) The private provision of public environment: Consumer preferences of organic production systems. Land Use Policy 26(3): 669-682.

Arnould EJ (2007) Should consumer citizens escape the market? Annals of the American Academy of Political and Social Science 611: 96-111.

Auger P and Devinney T (2007) Do what consumers say matter? The misalignment of preferences with unconstrained ethical intentions. Journal of Business Ethics 76(4): 361-383.

Auger P, Burke P, Devinney TM and Louviere JD (2003) What will consumers pay for social product features? Journal of Business Ethics 42(3): 281-304.

Barnett C, Clarke N, Cloke P and Malpass A (2005a) The political ethics of consumerism. Consumer Policy Review 15(2): 45-51.

Barnett C, Cloke P, Clarke N and Malpass A (2005b) Consuming ethics: Articulating the subjects and spaces of ethical consumption. Antipode 37(1): 23-45.

Beagan BL, Ristovski-Slijepcevic S and Chapman GE (2010) People are just becoming more conscious of how everything's connected: Ethical food consumption in two regions of Canada. Sociology 44(4): 1-19.

Becker H (1963) Outsiders: Studies in the Sociology of Deviance. New York, NY: Free Press.

Belcher KW, Germann AE and Schmutz JK (2007) Beef with environmental and quality attributes: Preference of environmental group and general population consumers in Saskatchewan, Canada. Agriculture and Human Values 24: 333-342.

Bondy T and Talwar V (2011) Through thick and thin: How fair trade consumers have reacted to the global recession. Journal of Business Ethics February 3: 1-19.

Bourdieu P (1984) Distinction: A Social Critique of the Judgment of Taste, trans. R Nice. Cambridge: Harvard University Press.

Bourdieu P (1986) The Forms of Capital. In: Richardson JG (ed.) Handbook of Theory and Research for the Sociology of Education. New York: Greenwood Press, 241-258.

Brown KR (2009) The social dynamics and durability of moral boundaries. Sociological Forum 24(4): 854-876. 
Brown E, Dury S and Holdsworth M (2009) Motivations of consumers that use local, organic fruit and vegetable box schemes in Central England and Southern France. Appetite 53(2): 183-188.

Burawoy M (2009) The Extended Case Method: Four Countries, Four Decades, Four Great Transformations, and One Theoretical Tradition. Berkeley, CA: University of California Press.

Cherrier H (2005) Using existential-phenomenological interviewing to explore meanings of consumption. In: Harrison R, Newholm T and Shaw D (eds) The Ethical Consumer. Thousand Oaks, CA: Sage Publications, 125-136.

Clavin B and Lewis A (2005) Focus groups on consumers' ethical beliefs. In: Harrison R, Newholm $\mathrm{T}$ and Shaw D (eds) The Ethical Consumer. Thousand Oaks, CA: Sage Publications, 173-188.

Cole NL (2008) Global capitalism organizing knowledge of race, gender and class: The case of socially responsible coffee. Race, Gender and Class 15(1/2): 170-187.

De Pelsmacker P, Driesen L and Rayp G (2005) Do consumers care about ethics? Willingness to pay for fair trade coffee. Journal of Consumer Affairs 39(2): 363-385.

DeVault M (1991) Feeding the Family. Chicago: University of Chicago Press.

Devinney TM, Auger P, Eckhardt G and Birtchnell T (2006) The other CSR. Stanford Social Innovation Review 4(3): 30-37.

Diamantopoulos A, Schlegelmilch B, Sinkovics R and Bohlen G (2003) Can sociodemographics still play a role in profiling green consumers? A review of the evidence and an empirical investigation. Journal of Business Research 56(4): 465-480.

Dolan C (2005) Fields of obligation: Rooting ethical sourcing in Kenyan horticulture. Journal of Consumer Culture 5(3): 365-89.

Douglas M (1966) Purity and Danger: An Analysis of Concepts of Pollution and Purity. London: Routledge and Kegan Paul.

DuPuis EM and Goodman D (2005) Should we go 'home' to eat?: Toward a reflexive politics of localism. Journal of Rural Studies 21(3): 359-371.

Durkheim E and Mauss M (1963) Primitive Classification. Chicago: University of Chicago Press.

Fotopoulos C and Krystallis A (2002) Organic product avoidance: Reasons for rejection and potential buyers' identification in a countrywide survey. British Food Journal 104(3/4/5): 233-260.

Gilbert D (2008) The American Class Structure in an Age of Growing Inequality. London: Sage Publications.

Goldthorpe JH (with Llewellyn C and Pane C) (1987) Social Mobility and Class Structure in Modern England. New York, NY: Oxford University Press.

Govindasamy R, Zurbriggen M, Italia J, Adelaja A, Nitzsche P and VanVranken R (1998) Farmers Markets: Consumer Trends, Preferences, and Characteristics. New Jersey Agricultural Experiment Station. P-0(2137)-77-98. Department of Agricultural, Food, and Resource Economics: Rutgers, State University of New Jersey.

Gracia A and de Magistris T (2008) The demand for organic foods in the South of Italy: A discrete choice model. Food Policy 33(5): 386-396.

Guthman J (2003) Fast food/organic food: Reflexive tastes and the making of 'yuppie chow'. Social and Cultural Geography 4(1): 45-58.

Guthman J (2008) 'If they only knew': Color blindness and universalism in California alternative food institutions. Professional Geographer 60(3): 387-397. 
Hinrichs CC (2000) Embeddedness and local food systems: Notes on two types of direct agricultural market. Journal of Rural Studies 16(3): 295-303.

Jabs J, Devine CM and Sobal J (1998) Model of the process of adopting vegetarian diets: Health vegetarians and ethical vegetarians. Journal of Nutrition Education 30: 196-202.

Johnston J (2008) The citizen-consumer hybrid: Ideological tensions and the case of Whole Foods Market. Theory and Society 37: 229-270.

Johnston J and Baumann S (2010) Foodies: Democracy and Distinction in the Gourmet Foodscape. New York, NY: Routledge.

Kezis A, Gwebu T, Peavey S and Cheng HT (1998) A study of consumers at a small Farmers' market in Maine: Results from a (1995) survey. Journal of Food Distribution Research 29(1): 91-99.

Lamont M (1992) Money, Morals, and Manners: The Culture of the French and the American Upper-Middle Class. Chicago, IL: University of Chicago Press.

Lamont M (2000) The Dignity of Working Men: Morality and the Boundaries of Race, Class and Immigration. Cambridge, MA: Harvard University Press.

Lamont M and Fournier M (1992) Cultivating Differences: Symbolic Boundaries and the Making of Inequality. Chicago, IL: University of Chicago Press.

Michaelidou N and Hassan LM (2010) Modeling the factors affecting rural consumers' purchase of organic and free-range produce: A case study of consumers' from the Island of Arran in Scotland, UK. Food Policy 35(2): 130-139.

Micheletti M (2003) Political Virtue and Shopping: Individuals, Consumerism and Collective Action. New York: Palgrave.

Morgan K (2010) Local and green, global and fair: The ethical foodscape and the politics of care. Environment and Planning A 42(8): 1852-1867.

Newholm T (2005) Case studying ethical consumers' projects and strategies. In: Harrison R, Newholm T and Shaw D (eds) The Ethical Consumer. Thousand Oaks, CA: Sage Publications, 107-124.

O'Donovan P and McCarthy M (2002) Irish consumer preference for organic meat. British Food Journal 104(3/4/5): 353-370.

Roberts JA (1996) Will the real socially responsible consumer please step forward? Business Horizons 39(1): 79-85.

Sassatelli R (2006) Virtue, responsibility and consumer choice: Framing critical consumerism. In: Brewer J and Trentmann F (eds) Consuming Cultures, Global Perspectives: Historical Trajectories, Transnational Exchanges. Oxford: Berg, 219-250.

Sassatelli R and Davolio F (2010) Consumption, pleasure and politics: Slow food and the politico-aesthetic problematization of food. Journal of Consumer Culture 10(2): 202-232.

Schwartz J (2000) Fighting Poverty with Virtue: Moral Reform and America's Urban Poor 1825-2000. Bloomington: Indiana University Press.

Smith C and Morton LW (2009) Rural food deserts: Low-income perspectives on food access in Minnesota and Iowa. Journal of Nutrition Education and Behavior 41(3): 176-187.

Starr MA (2009) The social economics of ethical consumption: Theoretical considerations and empirical evidence. Journal of Socio-Economics 38(6): 916-925.

Stiles BL (1998) Vegetarianism: Identity and experiences as factors in food selection. Free Inquiry in Creative Sociology 26(2): 213-225.

Swidler A (1986) Culture in action: Symbols and strategies. American Sociological Review 51 (April): 273-286. 
Swidler A (2001) Talk of Love: How Culture Matters. Chicago, IL: University of Chicago Press.

Tilly C (1993) Contentious repertoire in Great Britain, 1758-1834. Social Science History 17(20): 253-279.

van Kempen L, Muradian R, Sandóval C and Castañeda JP (2009) Too poor to be green consumers? A field experiment on revealed preferences for firewood in rural Guatemala. Ecological Economics 68(7): 2160-2167.

Weatherell C, Tregear A and Allinson J (2003) In search of the concerned consumer: UK public perceptions of food, farming and buying local. Journal of Rural Studies 19(2): 233-244.

Josee Johnston is Associate Professor of Sociology at the University of Toronto. She focuses her research on the sociological study of food, investigating aspects of culture, consumerism, politics, and the environment. Johnston co-authored (with Shyon Baumann) Foodies: Democracy and Distinction in the Gourmet Foodscape (Routledge, 2010), and has published articles in venues including American Journal of Sociology, Theory and Society, Signs: Journal of Women in Culture and Society, Gender and Society, and Antipode: A Radical Journal of Geography. Current research projects are focused on the following: (1) ethical consumption (funded by the Social Sciences and Humanities Research Council of Canada); (2) Family food practices (funded by the Canadian Institute for Health Research); and (3) Consumer motivations in alternative agricultural initiatives (funded by an Ontario Government Early Researcher Award).

Michelle Szabo is a $\mathrm{PhD}$ candidate in the Faculty of Environmental Studies at York University, Toronto. Her interests include the sociology of food and cooking; ethical consumption; gender and foodwork; and household food habits as they relate to health, sustainability and equity in the food system. Her dissertation examines the motivations for and meanings of domestic cooking among involved male domestic cooks. She has published articles in Agriculture \& Human Values as well as Food, Culture \& Society.

Alexandra Rodney is a third year PhD student at the University of Toronto, and a recipient of the Ontario Graduate Scholarship. As part of her doctoral research, she is writing an analysis of how infertility patients are portrayed in the media. Her research interests include health, culture, and gender, as well as use of the Internet for health support. 


\section{Appendix}

Appendix Table I. Summary of demographic data

\begin{tabular}{|c|c|}
\hline Family characteristics & Number of families \\
\hline Income - high & 7 \\
\hline Income - middle & 2 \\
\hline Income - low & 11 \\
\hline Education $^{12}$ - university degree or above & 11 \\
\hline Education - some post secondary & 6 \\
\hline Education - high school or less & 3 \\
\hline Race/ethnicity - White (Anglo-Saxon or European background) & 14 \\
\hline Race/ethnicity - non-White or of mixed heritage ${ }^{13}$ & 6 \\
\hline Class $^{14}$ - upper-middle & 7 \\
\hline Class - lower-middle & 8 \\
\hline Class - working class/working poor/ underclass & 5 \\
\hline
\end{tabular}

Appendix Table 2. Levels of engagement of families $(n=20)$ by class

\begin{tabular}{llll}
\hline Class & Strongly engaged & $\begin{array}{l}\text { Moderately } \\
\text { engaged }\end{array}$ & $\begin{array}{l}\text { Weakly } \\
\text { engaged }\end{array}$ \\
\hline Upper-middle & 4 & 1 & 2 \\
Lower-middle & 2 & 4 & 2 \\
Working class/working poor/underclass & 0 & 1 & 4 \\
Total & 6 & 6 & 8 \\
\hline
\end{tabular}

